\title{
Autosomal Dominant ANO5-Related Disorder Associated With Myopathy and Gnathodiaphyseal Dysplasia
}

Aziz Shaibani, MD, Shaida Khan, DO, and Marwan Shinawi, MD

Neurol Genet 2021;7:e612. doi:10.1212/NXG.0000000000000612
Correspondence

Dr. Shinawi

mshinawi@wustl.edu

\begin{abstract}
\section{Objective}

To investigate the molecular basis of muscle disease and gnathodiaphyseal dysplasia (GDD) in a large kindred with 11 (6 women and 5 men) affected family members.
\end{abstract}

\section{Methods}

We performed clinical assessment of 3 patients and collected detailed clinical and family history data on 8 additional patients. We conducted molecular genetic analyses on 5 patients using comprehensive neuromuscular disorder panels, exome sequencing (ES), and targeted testing for specific genetic variants. We analyzed the segregation of the muscle and bone phenotypes with the underlying molecular cause.

\section{Results}

The unique clinical presentation of recurrent episodes of rhabdomyolysis associated with muscle cramps, hyperCKemia, muscle hypertrophy, with absent or mild muscle weakness, as well as cemento-osseous lesions of the mandible, with or without bone fractures and other skeletal abnormalities, prompted us to look for the underlying molecular cause of the disorder in this kindred. Molecular testing revealed a missense variant in anoctamin 5 (ANO5) designated as c.1538C $>\mathrm{T}$; p.Thr513Ile, which was previously described in a large kindred with GDD. In silico analysis, searching publicly available databases, segregation analysis, as well as functional studies performed by another group provide strong evidence for pathogenicity of the variant. ES data in the proband excluded the contribution of additional genetic factors.

\section{Conclusions}

This report described the coexistence of muscle and bone phenotypes in the same patients with ANO5-related disorder. Our data challenge recent results that suggested complete dichotomy of these phenotypes and the proposed loss-of-function and gain-of-function mechanisms for the skeletal and muscle phenotypes, respectively. 


\section{Glossory}

$\mathrm{AD}=$ autosomal dominant; $\mathbf{A N O 5}=$ anoctamin 5; $\mathbf{A R}=$ autosomal recessive; $\mathbf{C K}=$ creatine kinase $\mathbf{C O F}=$ cemento-ossifying fibromas; ES = exome sequencing; GDD = gnathodiaphyseal dysplasia; LGMDR12 = limb-girdle muscular dystrophy-12; MD = muscle disease; MMD3 = Miyoshi muscular dystrophy-3; TMEM16 = transmembrane 16.

Anoctamin 5 (ANO5; MIM\# 608662) belongs to the transmembrane 16 (TMEM16) protein family. The gene has 22 exons and encodes a 913-amino acid protein and is not only abundantly expressed in skeletal and cardiac muscles but also found in growth plate chondrocytes and in osteoblasts, illustrating its important role in muscle and bone development and function.

Pathogenic ANO5 variants cause 2 distinct disorders with no overlapping features. Heterozygous variants are associated with autosomal dominant $(\mathrm{AD})$ gnathodiaphyseal dysplasia (GDD; MIM\# 166260), characterized by cemento-osseous lesions of the mandible and maxilla, bowing/sclerosis of tubular bones, and generalized bone fragility with recurrent fractures. ${ }^{1}$ Biallelic variants cause 2 autosomal recessive (AR) myopathies: Miyoshi muscular dystrophy-3 (MMD3; MIM\# 613319) and limb-girdle muscular dystrophy-12 (LGMDR12; MIM\# 611307). The spectrum of clinical findings in the AR disease ranges from asymptomatic hyperCKemia, exercise-induced myalgia, and predominantly lateonset proximal muscle weakness (LGMDR12) to early-onset calf distal myopathy $(\mathrm{MMD} 3)^{2}{ }^{2}$ Herein, we report a large kindred with multiple family members presenting with muscle and skeletal findings that segregated with a missense ANO5 variant, which was previously described in a large kindred with GDD.

\section{Methods}

\section{Standard Protocol Approvals, Registrations, and Patient Consents}

Written informed consent and authorization for publication were obtained from patients II-2, III-1, III-4, III-10, and IV-6. The Washington University in St. Louis Media Authorization for the Use and Disclosure of Protected Health Information form was used for all patients.

\section{Genetic Testing}

Molecular genetic analyses were performed on 5 patients and included comprehensive neuromuscular disorder panels, exome sequencing (ES), and targeted testing for specific genetic variants, as detailed in the Supplementary Material (links.lww.com/NXG/A439).

\section{Data Availability}

Anonymized data will be shared by request from any qualified investigator.

\section{Results}

\section{Patients Report}

The proband (III-1) (Figure 1) is a 46-year-old White man who presented with episodes of rhabdomyolysis with severe painful muscle cramps since age 6 years. The cramps involved legs, arms, and abdominal muscles; occurred 3-5 times a year; lasted for 5-7 days; disrupted his daily life activities; and were associated with hyperCKemia with the highest creatine kinase (CK) value at 8,000 IU/L (normal 207-250). Between episodes, he complained of generalized fatigue and muscle weakness. He also had several bone fractures between ages 7 and 17 years, including 8 fractures in his left forearm and 1 fracture in left femur. On physical examination, he had generalized muscle hypertrophy and maintained normal strength in all muscles. His workup included a normal EMG and a muscle biopsy, which revealed mild, nonspecific myopathic changes (Figure 2). His skeletal survey showed generalized diaphyseal thickening of long bones (Figure 3).

Patient III-10 (Figure 1), maternal cousin of the proband, is a 42-year-old woman who presented with episodes of rhabdomyolysis with exertional painful muscle cramps and weakness associated with hyperCKemia with highest $\mathrm{CK}$ value at 6,000 $\mathrm{IU} / \mathrm{L}$. Her symptoms began in her late 20 s and were limited to her calves. Throughout the years, her symptoms progressed to diffuse muscle pains, which limited her activity. Over the past 4 years, she started complaining of increased shortness of breath and fatigue. At age 36 years, she had compartment syndrome requiring emergent fasciotomy. She had 3 fractures in her arm and leg between ages 5 and 9 years and had multiple cemento-ossifying fibromas (COFs) in her mandible. Neurologic examination showed muscle hypertrophy in the biceps, forearms, and calves bilaterally; muscle weakness $4+/ 5$ on hip flexion bilaterally; and full strength throughout all other muscles. Reflexes were diffusely reduced. Muscle biopsy showed atrophy of mostly type IIB fibers suggesting disuse and internal nuclei in occasional fibers. EMG and nerve conduction studies were normal.

The son of patient III-10, IV-6 (Figure 1) is 20 years old who also presented with rhabdomyolysis with exertional painful muscle cramps, muscle hypertrophy, and hyperCKemia. His muscle symptoms began at age 16 years with severe diffuse muscle stiffness and pain, both exacerbated by physical activity. CK levels at baseline were elevated at the 10-fold normal range; however, there have been several episodes of rhabdomyolysis with CK values in the 25,000 IU/L range; 4 of these episodes at age 18-19 years were complicated by the compartment syndrome involving all 4 extremities requiring multiple fasciotomies. One of these episodes led to left peroneal nerve injury. He also had multiple mandibular COFs first detected at 9 years of age and required debulking and extraction of many of his lower teeth at 9 and 12 years of age. 


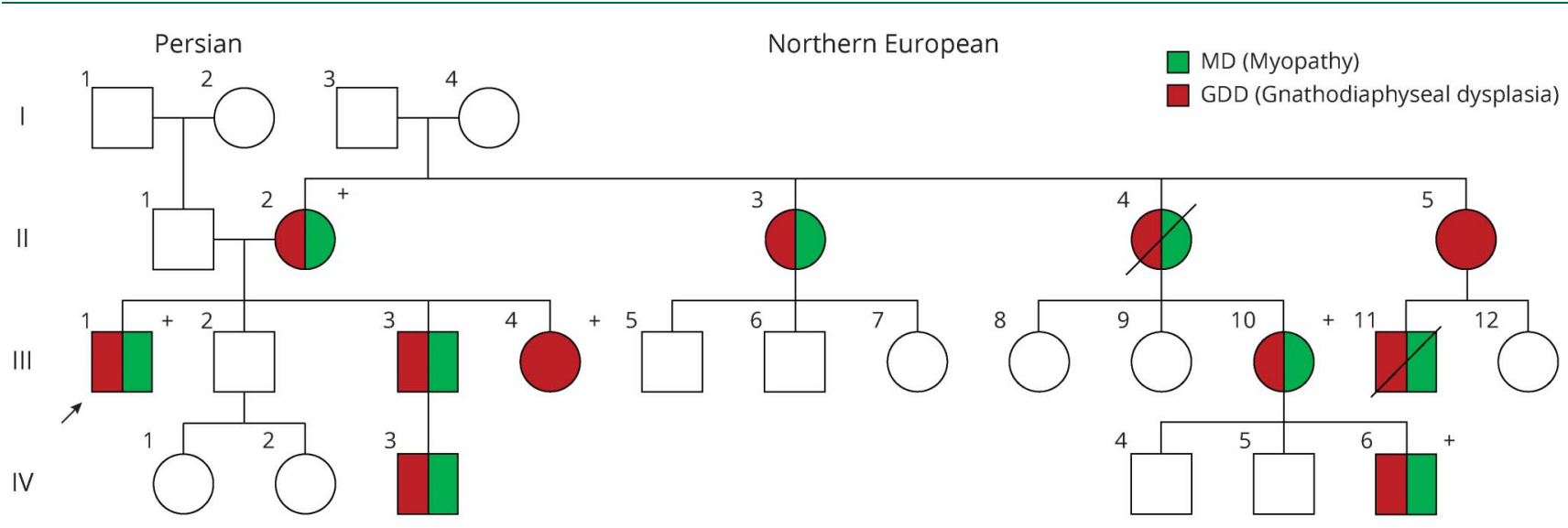

Pedigree of the large family described in this report. Circles are for female patients and squares for male patients. Dark red indicates the presence of MD, and green indicates findings consistent with GDD. Roman numerals are for generations in the kindred, and numerical numbers are for family members in each generation. (+) indicates patients who have been analyzed for the ANO5 variant. ANO5 = anoctamin 5; GDD = gnathodiaphyseal dysplasia; MD = muscle disease.

He also had fractures in his clavicle and spine at age 14 and 16 years, respectively. Neurologic examination showed diffuse muscle hypertrophy, predominantly in the calves and forearms. There were $4 / 5$ hip flexion bilaterally and $2 / 5$ left ankle dorsiflexion and eversion weakness. Deep tendon reflexes were diffusely absent. Muscle biopsy showed occasional muscle fibers with internal nuclei, but otherwise nonspecific. EMG revealed mild myopathic motor units in the deltoid, otherwise normal.

The family history (Figure 1) was significant for 5 additional affected female patients, all had COFs and 3 had recurrent muscle cramps, and for 3 affected male patients with recurrent episodes of muscle cramps and COFs, as detailed in the Supplementary Material (links.lww.com/NXG/A439).

\section{Molecular Results}

Molecular testing of patients II-2, III-1, III-4, III-10, and IV-6 revealed the ANO5 (NM_213599.2) variant p.Thr513Ile (ACC $>$ ATC): c. $1538 \mathrm{C}>\mathrm{T}$. The proband also had the variant c.4604G>A; p.Arg1535His in COL6A3 (NM_004369.4), which was not detected in all family members who underwent molecular testing. ES for the proband confirmed the maternal inheritance of the ANO5 variant, but no other variants were identified.

\section{Discussion}

We reported a large kindred with multiple family members presenting with an $\mathrm{AD}$ disorder featuring recurrent episodes of muscle cramps, generalized muscle weakness, muscle hypertrophy, hyperCKemia, and bone findings consistent with GDD. The 2 phenotypes largely segregated with the p.Thr513Ile ANO5 variant. This report documented the coexistence of the muscle and bone phenotypes in patients heterozygous for pathogenic ANO5 variants. One previous study reported the presence of "facial dysplasia with a prominent jaw" in a patient with AR ANO5-related disorder, but no convincing data were provided to support the presence of GDD. ${ }^{3}$ The absence of the COL6A3 variant in other family members and negative ES in the proband highly support that
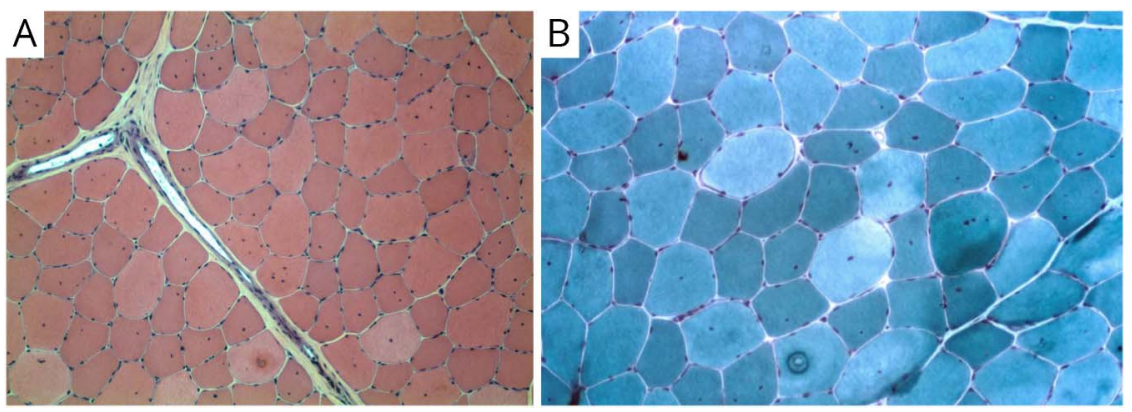

Muscle biopsy findings in the proband (III-1). H\&E (A) and Gomori trichrome (B) stains (magnified at $100 \times$ ) showing mild variation of fiber size and increased internal nuclei; both are nonspecific myopathic findings. $A D=$ autosomal dominant; ANO5 = anoctamin 5 . 

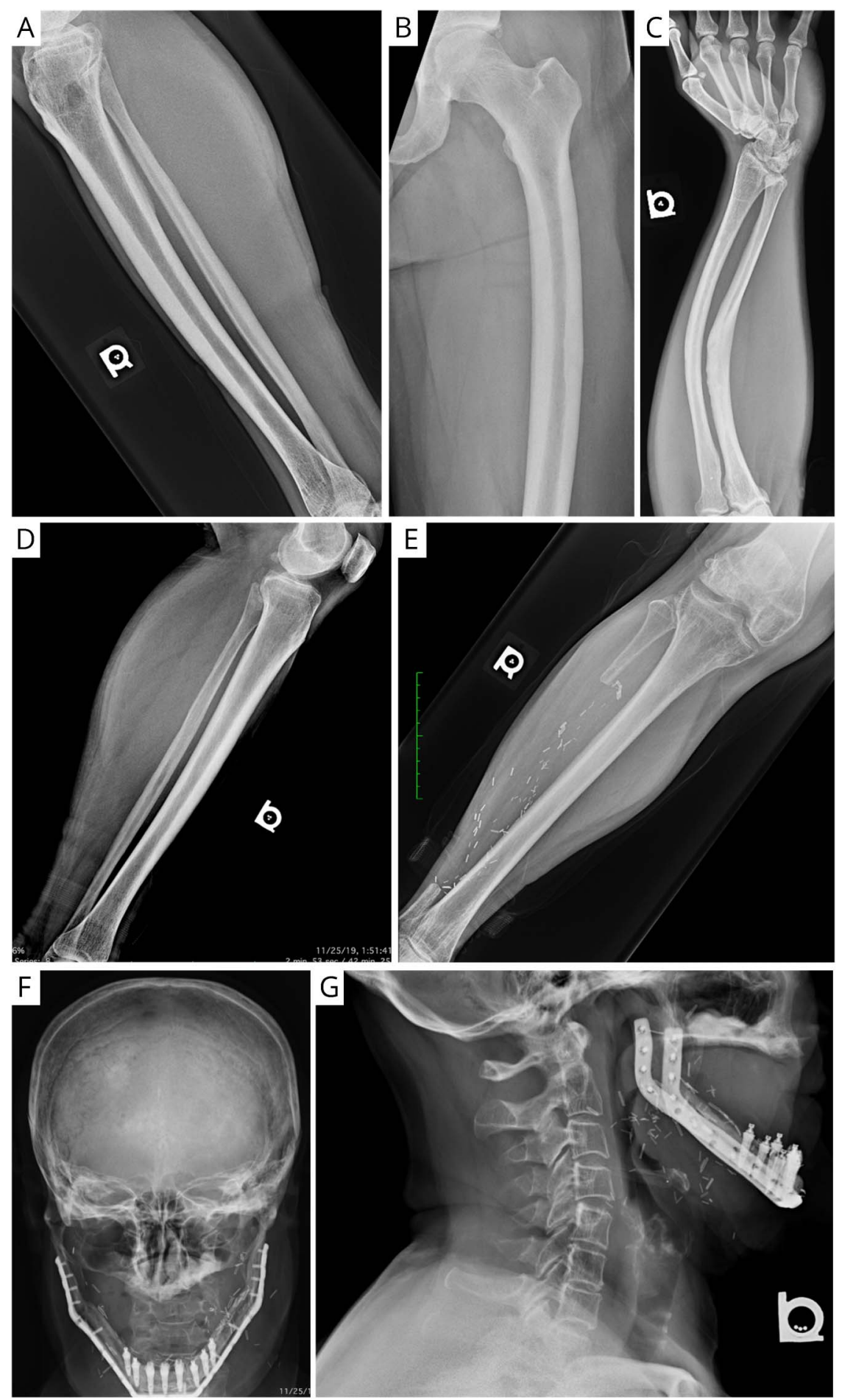

Radiological findings in the proband (III-1) (A-C) and his mother (II-2) (D-G). Lateral view of right tibia and fibula (A) and AP view of left femur (B) showing diaphyseal thickening and reduced tabulation of the tibia. Lateral view of the forearm (C) showing significant deformities secondary to repeat fractures. Lateral (D) and AP (E) views of left and right tibia and fibula, respectively, of patient II-2 showing mid shaft cortical thickening and a complicated fracture of right fibula. AP and lateral skull views of patient II-2 showing postoperative reconstruction of mandible after debulking of $\operatorname{COF}(F$ and $\mathrm{G}$ ) and severe osteopenia in cervical spine $(G)$. $A D=$ autosomal dominant; $C O F=$ cemento-ossifying fibromas. the ANO5 variant is the cause of muscle disease. Our data expand the phenotypic heterogeneity of ANO5-related disorder and support the presence of combined muscle and bone phenotypes as a new $\mathrm{AD}$ subtype. It remains to be determined whether this new entity is unique for this specific ANOS variant or represents an emerging, probably underdiagnosed, phenotype.
Patients with the AR ANO5-related muscle disease exhibit a spectrum of clinical manifestations with variable severity and age at onset. Two female patients in this kindred did not report muscle symptoms, consistent with prior descriptions of reduced penetrance and milder symptoms in female patients with ANO5-related muscle disease. ${ }^{4}$ The possibility remains that these 2 female patients have asymptomatic muscle 
involvement. Muscle weakness is considered a typical finding in this disease but was absent or mild in the 3 patients evaluated in this study. The variation in muscle strength among patients in this study can be explained by interexaminer variability, variable expressivity related to additional genetic modifiers not detected through current genetic tests, or higher burden of muscle disease and rhabdomyolysis that led to more persistent muscle weakness in patient IV-6. The age at onset of muscle symptoms in the 3 patients was earlier than that reported among patients with the mild form of the AR disease. The prominent finding in our cohort was the episodic nature of muscle symptoms, ranging from muscle cramps and rhabdomyolysis to compartment syndrome, which affected patients' quality of life and their daily life activities. While rhabdomyolysis has been occasionally reported in ANO5related muscle disorder, ${ }^{5}$ there have been no reports of compartment syndrome. Furthermore, muscle cramps have been rarely reported in the AR ANO5-related muscle disorder. $^{6}$ The underlying physiologic mechanism of muscle cramps is not well understood, but different hypotheses have been proposed. ${ }^{7}$ The nonspecific myopathic findings in muscle biopsy and normal or mild myopathic motor units on EMG are consistent with previous reports. ${ }^{5}$

To date, 9 missense ANO5 variants have been reported in heterozygous state, ${ }^{1,8} 3$ of which, including p.Thr513Ile, are located in exon 15. Despite the fact that Thr513 is not evolutionarily conserved, several lines of evidence support pathogenicity of the ANO5 variant. First, it has not been observed in healthy control databases. Second, this variant segregates well with the combined bone and muscle phenotypes in this kindred and was reported in association with GDD in multiple individuals from a single family. ${ }^{9}$ Of interest, 1 patient in the previously reported family had elevated CK levels, but no additional details about muscle disease were provided. ${ }^{9}$ Third, recent published functional studies demonstrated increased phospholipid scrambling. ${ }^{10}$

ANO5 protein is predominantly localized intracellularly, with smaller localization to the plasma membrane. It acts as a calcium-activated chloride channel or phospholipid scramblase. ${ }^{11}$ Lack of ANO5 impairs the repair ability of injured myoblasts through dysregulated calcium homeostasis. ${ }^{12}$ ANO5 mutant protein carrying the p.Thr513Ile variant mediates scramblase activity independent of elevated cytosolic calcium and carries large outward currents even at extremely low intracellular calcium, suggesting a gain-of-function mechanism. ${ }^{8}$ On the other hand, variants associated with the muscle phenotype were associated with a loss-of-function phenotype in the same in vitro model. ${ }^{10}$ However, this phenotypic and molecular dichotomy is not supported by our data, and therefore, alternative mechanistic models should be investigated. Furthermore, mouse models yielded conflicting results, including sarcolemma repair abnormalities and defective myoblast regeneration and fusion, ${ }^{13}$ lack of muscle phenotype ${ }^{14}$ GDD phenotype ${ }^{15}$ in Ano5-knockout mice, as well as absence of skeletal phenotype in a knock-in model of a
GDD-related mutation. ${ }^{16}$ These data indicate that additional studies are needed to delineate the ANO5 function and the pathomechanisms of the 2 associated phenotypes.

Limitations of this study include neurologic evaluation performed by different medical professionals, lack of full clinical assessment for all family members in this kindred, and targeted genetic testing for the familial ANO5 variant or neuromuscular panels except for the proband who had ES.

\section{Acknowledgment}

The authors thank the patients and their families described for participating in this study and for being engaged, dedicated, and curious.

\section{Study Funding}

The authors report no targeted funding.

\section{Disclosure}

A. Shaibani, S. Khan, and M. Shinawi report no disclosures. Go to at Neurology.org/NG for full disclosures.

\section{Publication History}

Received by Neurology: Genetics December 19, 2020. Accepted in final form May 3, 2021.

\section{Appendix Authors}

\begin{tabular}{|c|c|c|}
\hline Name & Location & Contribution \\
\hline $\begin{array}{l}\text { Aziz } \\
\text { Shaibani, } \\
\text { MD }\end{array}$ & $\begin{array}{l}\text { Nerve and Muscle Center of } \\
\text { Texas \& Departments of } \\
\text { Medicine, Baylor College of } \\
\text { Medicine, Houston, TX }\end{array}$ & $\begin{array}{l}\text { Revision of the article for } \\
\text { content, including medical } \\
\text { writing for content; major role } \\
\text { in the acquisition of data; study } \\
\text { concept or design; and analysis } \\
\text { of data }\end{array}$ \\
\hline
\end{tabular}

Shaida Department of Neurology, UT Revision of the article for content, Khan, DO Southwestern Medical including medical writing for Center, Dallas, TX content; major role in the acquisition of data; and analysis or interpretation of data

\begin{tabular}{lll}
\hline $\begin{array}{l}\text { Marwan } \\
\text { Shinawi, }\end{array}$ Lashington University in St. & Drafting/revision of the article \\
MD & for content, including medical \\
writing for content; major role & in the acquisition of data; study \\
& concept or design; and analysis \\
& or interpretation of data
\end{tabular}

\section{References}

1. Otaify GA, Whyte MP, Gottesman GS, et al. Gnathodiaphyseal dysplasia: severe atypical presentation with novel heterozygous mutation of the anoctamin gene (ANO5). Bone. 2018;107:161-171.

2. Savarese M, Di Fruscio G, Tasca G, et al. Next generation sequencing on patients with LGMD and nonspecific myopathies: findings associated with ANO5 mutations. Neuromuscul Disord. 2015;25(7):533-541.

3. Witting N, Duno M, Born AP, Vissing J. LGMD2L with bone affection: overlapping phenotype of dominant and recessive ANO5-induced disease. Muscle Nerve. 2012;46(5):829-830.

4. Nigro V, Savarese M. Genetic basis of limb-girdle muscular dystrophies: the 2014 update. Acta Myol. 2014;33(1):1-12.

5. Silva AMS, Coimbra-Neto AR, Souza PVS, et al. Clinical and molecular findings in a cohort of ANO5-related myopathy. Ann Clin Transl Neurol. 2019;6(7):1225-1238.

6. Bohlega S, Monies DM, Abulaban AA, Murad HN, Alhindi HN, Meyer BF. Clinical and genetic features of anoctaminopathy in Saudi Arabia. Neurosciences. 2015;20(2): 173-177. 
7. Giuriato G, Pedrinolla A, Schena F, Venturelli M. Muscle cramps: a comparison of the two-leading hypothesis. J Electromyogr Kinesiol. 2018;41:89-95.

8. Di Zanni E, Gradogna A, Picco C, Scholz-Starke J, Boccaccio A. TMEM16E/ANO5 mutations related to bone dysplasia or muscular dystrophy cause opposite effects on lipid scrambling. Hum Mutat. 2020;41(6):1157-1170.

9. Marconi C, Brunamonti Binello P, Badiali G, et al. A novel missense mutation in ANO5/TMEM16E is causative for gnathodiaphyseal dyplasia in a large Italian pedigree. Eur J Hum Genet. 2013;21(6):613-619.

10. Di Zanni E, Gradogna A, Scholz-Starke J, Boccaccio A. Gain of function of TMEM16E/ANO5 scrambling activity caused by a mutation associated with gnathodiaphyseal dysplasia. Cell Mol Life Sci. 2018;75(9):1657-1670.

11. Boccaccio A, Di Zanni E, Gradogna A, Scholz-Starke J. Lifting the veils on TMEM16E function. Channels. 2019;13(1):33-35.
12. Chandra G, Defour A, Mamchoui K, et al. Dysregulated calcium homeostasis prevent plasma membrane repair in Anoctamin 5/TMEM16E-deficient patient muscle cells. Cell Death Discov. 2019;5(1):118.

13. Griffin DA, Johnson RW, Whitlock JM, et al. Defective membrane fusion and repair in Anoctamin5-deficient muscular dystrophy. Hum Mol Genet. 2016;25(10):1900-1911.

14. Xu J, El Refaey M, Xu L, et al. Genetic disruption of Ano5 in mice does not recapitulate human ANO5-deficient muscular dystrophy. Skelet Muscle. 2015;5(1):43.

15. Wang X, Liu X, Dong R, Liang C, Reichenberger EJ, Hu Y. Genetic disruption of anoctamin 5 in mice replicates human gnathodiaphyseal dysplasia (GDD). Calcif Tissue Int. 2019;104(6):679-689.

16. Rolvien $\mathrm{T}$, Avci $\mathrm{O}$, von Kroge $\mathrm{S}$, et al. Gnathodiaphyseal dysplasia is not recapitulated in a respective mouse model carrying a mutation of the Ano5 gene. Bone Rep. 2020;12: 100281 . 


\section{Neurology

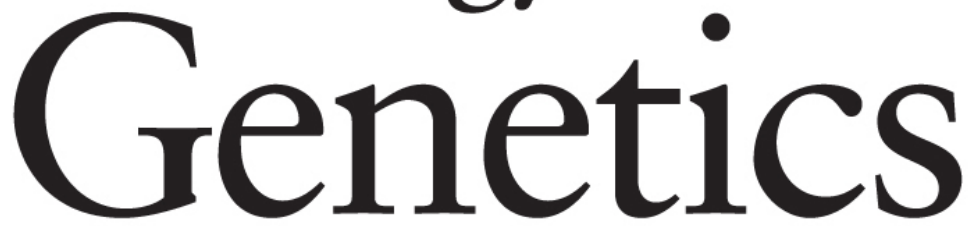

\section{Autosomal Dominant ANO5-Related Disorder Associated With Myopathy and Gnathodiaphyseal Dysplasia \\ Aziz Shaibani, Shaida Khan and Marwan Shinawi \\ Neurol Genet 2021;7; \\ DOI 10.1212/NXG.0000000000000612}

This information is current as of July 16, 2021

Updated Information \& Services

References

Subspecialty Collections

Permissions \& Licensing

Reprints including high resolution figures, can be found at: http://ng.neurology.org/content/7/4/e612.full.html

This article cites 16 articles, 0 of which you can access for free at: http://ng.neurology.org/content/7/4/e612.full.html\#\#ref-list-1

This article, along with others on similar topics, appears in the following collection(s):

All Genetics

http://ng.neurology.org//cgi/collection/all_genetics

All Neuromuscular Disease

http://ng.neurology.org//cgi/collection/all_neuromuscular_disease Ion channel gene defects

http://ng.neurology.org//cgi/collection/ion_channel_gene_defects Muscle disease

http://ng.neurology.org//cgi/collection/muscle_disease

Information about reproducing this article in parts (figures,tables) or in its entirety can be found online at:

http://ng.neurology.org/misc/about.xhtml\#permissions

Information about ordering reprints can be found online: http://ng.neurology.org/misc/addir.xhtml\#reprintsus

Neurol Genet is an official journal of the American Academy of Neurology. Published since April 2015, it is an open-access, online-only, continuous publication journal. Copyright Copyright $\odot 2021$ The Author(s). Published by Wolters Kluwer Health, Inc. on behalf of the American Academy of Neurology.. All rights reserved. Online ISSN: 2376-7839.

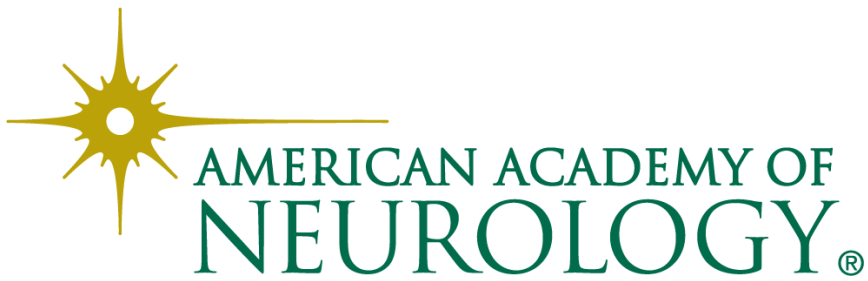

